\title{
Performance and Stability Analysis of Sub-stiffening for Mechanical Buckling and Post Buckling: A Selective Study
}

\author{
Hemza Layachi and Yuan-ming Xu \\ School of Aeronautic Science and Engineering, Beihang University, Beijing 100191, China
}

\begin{abstract}
The recent work is a selective study of different types and shapes of stiffeners and sub-stiffeners. The aim is to get an optimum design model of the sub-stiffened panels. We provide a variety of parameters to enhance the stability performance of sub-stiffened panels. We correspondingly perform the numerical study under ABAQUS 6.13 using the RIKS algorithm in the object of defining the critical loads for both buckling and post-buckling; the ultimate strength load represents the initial structure damage. Comparing to a linear sub-stiffened panel, the simulation results show that the grid and curvilinear sub-stiffening can improve the stability performance.
\end{abstract}

\section{Introduction}

Metallic Sub-stiffened panels in aerospace application have to be optimized in manner to remain stable against loading and reduced in mass. Several recent researches have inspected the possibility to reach an optimum model in order to extend the critical load to buckle and save the weight [1]-[3]. It is important to investigate the stability of the sub-stiffened panels against buckling; predictive, parametric, and experimental studies has defined the different buckling modes that can occur due to different loading [4],[5]. The mathematical formulation of buckling issue considers the type of loading which the panel is exposed, the dimensions of the panel and its material proprieties [6]-[8] and [9]. The panel configuration is another important argument in the study of its stability [10]-[12] and [13], the arrangement of the stiffeners and sub-stiffeners is essential. In our study, we will go through the analysis of the stiffened panel's stability. Thus, numerous parameters will be investigated in aim to increase the overall performance.

Buckling of sub-stiffened panels may occur due to different loading types, the instability process passes from local to global. Here under, we briefly introduce the different buckling modes:

\subsection{Local buckling}

Local buckling is represented when the connection between the plate and the stiffener does not displace vertically. It represents the buckling of the plate or the stiffener without the displacing in the vertical connection.

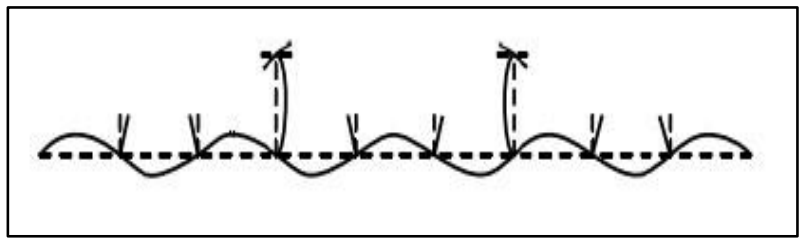

Figure 1. Sub-stiffened panel local buckling.

\subsection{Torsional Buckling}

Similar to local buckling mode, the difference is that the stiffeners flange are sufficiently stiff to keep that junction straight.

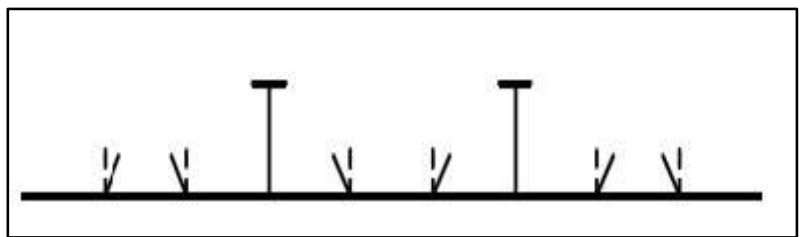

Figure 2. Sub-stiffened panel torsional buckling.

\subsection{Partial buckling}

Considering the spaces between the stiffeners, if the substiffener remains unbuckled with a torsional buckling mode, the partial buckling mode occurs.

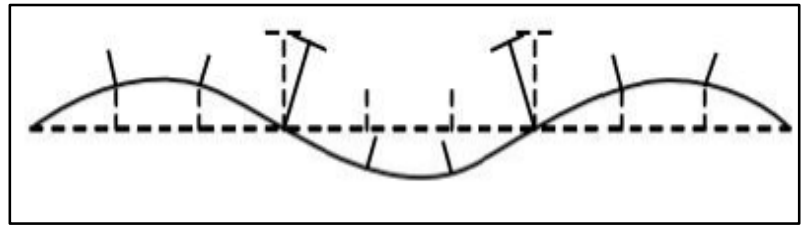

Figure 3. Sub-stiffened panel partial buckling. 


\subsection{Overall buckling}

It is the buckling mode that leads to total deformation of the skin and stiffeners at the same time, the local or torsional buckling mode is extended to a complete stiffened panel including several stiffeners.

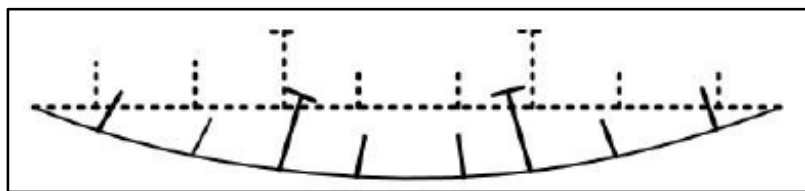

Figure 4. Sub-stiffened panel overall buckling.

The study of post buckling, as the name suggests, describes the behavior of a structure after the critical buckling load[14], [15],. In elastic domain, the stiffened panel can carry additional load when it is locally buckled, and that buckled surface are permissible along the width of the panel. When the whole panel buckles all as a column, it reaches the global buckling, moreover, it cannot carry more loads, it is the limit to failure [16],[17] and [18].

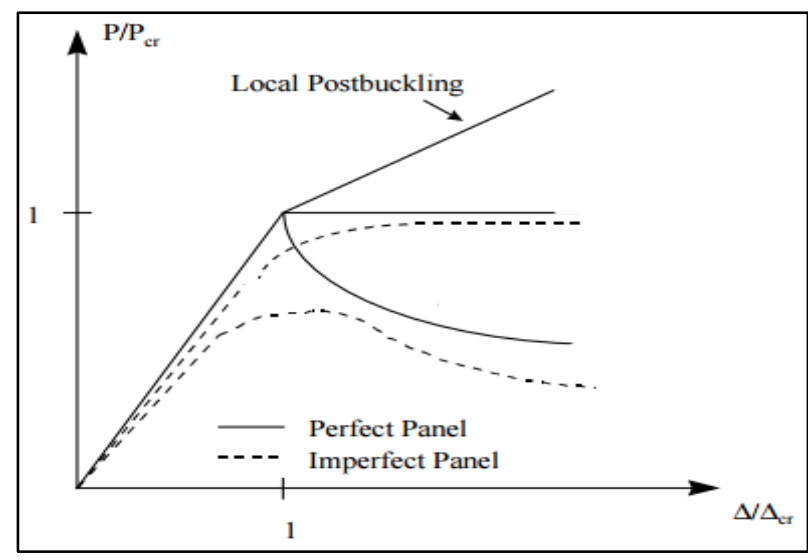

Figure 5. Linear and non-linear behavior of panels.

\section{Problem formulation}

Assuming that the sub-stiffened panel is exposed to a uniaxial compression in the direction of the stiffeners, and concealed on it transversal boundary conditions, the buckling of the panel will occur at the critical load.

The configuration of the panel and its boundary conditions are shown in the figure bellow,

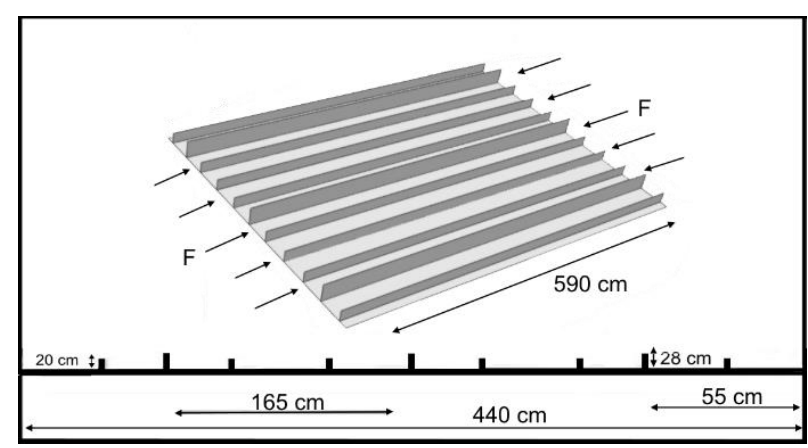

Figure 6. Prismatic sub-stiffened panel dimensioning.

In addition to the dimension given in figure 4 , the Table 1 gives more design variables and mechanical proprieties of the manufactured panel in question,

Table 1. Prismatic sub-stiffened panel design variables and mechanical properties.

\begin{tabular}{|c|c|c|c|}
\hline \multicolumn{2}{|c|}{ Design Variables } & \multicolumn{2}{c|}{ Mechanical properties } \\
\hline $\begin{array}{c}\text { Prismatic sub-stiffened } \\
\text { panel (A) }\end{array}$ & Aluminum alloy & $2024 \mathrm{~T} 3$ \\
\hline $\begin{array}{c}\text { Plate } \\
\text { thickness }\end{array}$ & $1.9 \mathrm{~mm}$ & Density $\left(\mathrm{Kg} / \mathrm{m}^{3}\right)$ & 2770 \\
\hline $\begin{array}{c}\text { Stiffeners } \\
\text { thickness }\end{array}$ & $2.8 \mathrm{~mm}$ & Young modulus & $73.1 \mathrm{GPa}$ \\
\hline Sub-thickness & $2.8 \mathrm{~mm}$ & Poisson's ratio & 0.33 \\
\hline $\begin{array}{c}\text { Distance per } \\
\text { stiffener/sub } \\
\text { stiffener }\end{array}$ & $55 \mathrm{~cm}$ & $\begin{array}{c}\text { Expansion } \\
\text { module }\end{array}$ & $2.3210^{-5}$ \\
\hline Total mass & $2.128 \mathrm{Kg}$ & Yield stress & $324 \mathrm{MPa}$ \\
\hline
\end{tabular}

Buckling analysis: at the loading limit, the structure starts to buckle, which leads to the limits of the elastic range. If the panel buckling response is local to partial as presented in the section before, the structure can carry more load before it buckles on an overall mode (post buckling range).

Post buckling analysis: the panel has not overall buckled, the stability of the stiffened panels will be standing up on the resistance of the stiffeners. Each stiffener will be analyzed individually. The collapse of the entire panel will occur when all the stiffeners can carry no additional load. At this range, the panel will undergo on local plastic deformation.

Collapse behavior: it represents the full plasticization of the structure, it cannot sustain more load, and the damage of the structure is predictable.

\section{Methodology}

The numerical analysis is based on comparative study of three kinds of sub-stiffened panels. All of them have the same mechanical proprieties and almost equal in mass. The aim is to select the best configuration that guarantee the panel stability under uniaxial compression load and delivers enhanced performance. The stiffeners and the sub-stiffeners are a reinforcement for a better stability of the panel in a mechanical aspect but it is against the concept of weight saving.

The design variable will be the dimensioning of the stiffeners and sub-stiffeners including the number of stiffeners and sub-stiffeners in the panel's cross section, the type of the sub-stiffening and the thickness of the plate section. We give two new concepts of sub-stiffeners that increase the stiffened panels stability along the plan, the first one is a grid sub-stiffened and the second is a curvilinear sub-stiffened. After an overall study, we adopt to use three sub-stiffeners in a cross section for some design and manufacturing reasons. Table 2 represents the two proposed design panels.

Our simulation output are load limit for buckling and post buckling, it is denoted as critical load and bearing ultimate load respectively. We cannot ignore the stresses caused by these loads along the panel $\sigma_{S}$. The gain 
percentage is based on ratio limit yield $\sigma_{s}$ to maximum mises stress caused by them. The interpolation of the variables in design is taking the prismatic sub-stiffened as a benchmark panel. $x_{i}$ Are the input design, we list the thickness for stiffeners and sub-stiffeners $t_{s t}$, their height $h_{s t}$, and plate thickness $t_{p}$, they should not exceed what the prismatic possess $t_{s t-\max }, h_{s t-\max }, t_{p-\max }$. Looking for a better material distribution along the plan, regarding the behavior of the three panels for the uniaxial compression force, we conclude the effect of each parameter listed in Table 2.

$$
\left\{\begin{array}{c}
\sigma_{\text {max }}<\sigma_{\mathrm{s}} \\
\mathrm{t}_{\mathrm{st}} \leq \mathrm{t}_{\mathrm{st}-\max } \\
\mathrm{h}_{\mathrm{st}} \leq \mathrm{h}_{\mathrm{st}-\max } \\
\mathrm{t}_{\mathrm{p}} \leq \mathrm{t}_{\mathrm{p}-\max } \\
\mathrm{x}_{\text {min }}<\mathrm{x}_{\mathrm{i}}<\mathrm{x}_{\max }, \mathrm{i}=1, \ldots, \mathrm{n}
\end{array}\right.
$$

Table 2. Proposed design dimensions.

\begin{tabular}{|c|c|c|}
\hline Proposed designs & (B) & (C) \\
\hline Plate thickness & $1.80 \mathrm{~mm}$ & $1.90 \mathrm{~mm}$ \\
\hline $\begin{array}{l}\text { Distance between } \\
\text { stiffeners }\end{array}$ & $165.00 \mathrm{~mm}$ & $165.00 \mathrm{~mm}$ \\
\hline Initial distance & $55.00 \mathrm{~mm}$ & $55.00 \mathrm{~mm}$ \\
\hline Stiffener thickness & $2.80 \mathrm{~mm}$ & $2.80 \mathrm{~mm}$ \\
\hline High of stiffeners & $28.00 \mathrm{~mm}$ & $28.00 \mathrm{~mm}$ \\
\hline High of sub-stiffeners & $16.50 \mathrm{~mm}$ & $16.32 \mathrm{~mm}$ \\
\hline $\begin{array}{l}\text { Distances between } \\
\text { sub-stiffeners }\end{array}$ & $55.00 \mathrm{~mm}$ & $55.00 \mathrm{~mm}$ \\
\hline $\begin{array}{l}\text { Thickness of sub- } \\
\text { stiffeners }\end{array}$ & $2.32 \mathrm{~mm}$ & $2.35 \mathrm{~mm}$ \\
\hline Total mass & $2.126 \mathrm{Kg}$ & $2.133 \mathrm{Kg}$ \\
\hline
\end{tabular}

\section{Results and discussion}

\subsection{Buckling analysis}

The simulation results at the reached eigenvalue show that the structure $\mathrm{B}$ provide higher performance ratio (96\%) comparing to the other structures, while the structure (C) represents a lesser loss of strength, which is due to the inadequate curving to uniaxial forces in its direction.

Table 3. Buckling results.

\begin{tabular}{|c|c|c|c|}
\hline Structure panel design & $\mathrm{A}$ & $\mathrm{B}$ & $\mathrm{C}$ \\
\hline Critical load (Kn ) & 212.2 & 222.4 & 211.8 \\
\hline $\begin{array}{c}\text { Equivalent Mises stress } \\
\text { (Mpa ) }\end{array}$ & 295.5 & 312.3 & 278 \\
\hline Buckling mode & Partial & Local & Local \\
\hline Gain & $91 \%$ & $96 \%$ & $85 \%$ \\
\hline
\end{tabular}

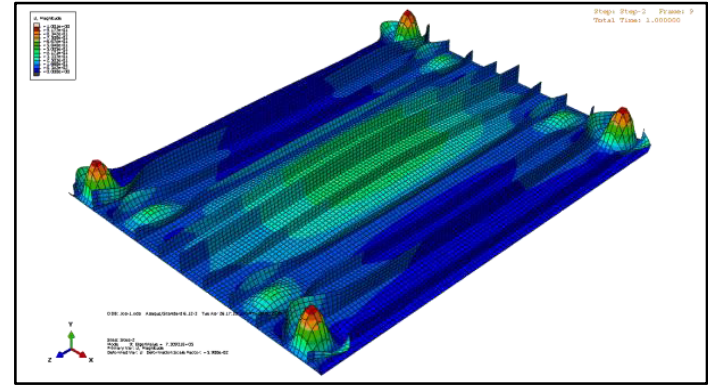

(A)

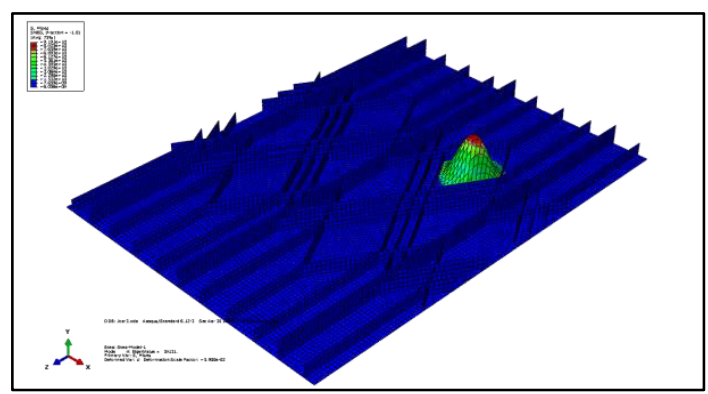

(B)

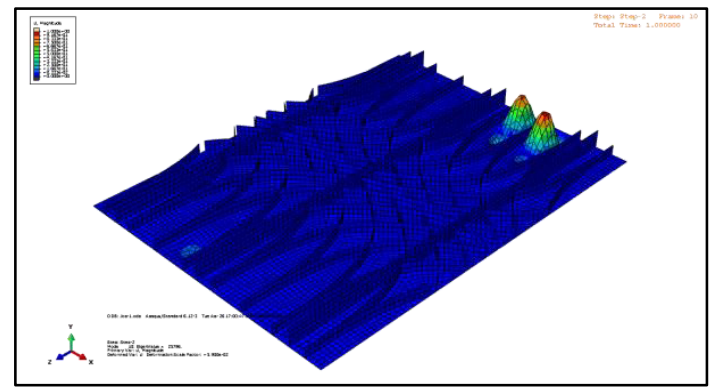

(C)

Figure 7. First Buckling modes of sub-stiffened panels (Case A, $\mathrm{B}$ and $\mathrm{C})$.

The great advantage of the proposed design (B) and (C) is that, both structures buckle locally in a first step (skin buckling with a great decrease of the half wavelet comparing to the benchmark case that represents a partial mode of buckling, it is just one step closer to the overall buckling (catastrophic).

\subsection{Post buckling analysis}

Figure 3 shows the numerical results of ultimate loading capacity. After that critical load, the sub-stiffened panels will collapse: the structure B reaches a greater strength capacity with a critical load at $383 \mathrm{KN}$, in addition to the transverse reinforcement that help to avoid the overall buckling also, possess rational continuity along its longitudinal axis in both stiffeners and sub-stiffeners. The design guidelines of such a structure start with ensuring the stability of the panel along the direction of the loading. As in that case, the stiffeners are oriented in the longitudinal axis of the load first, the grid sub-stiffens are a second reinforcement for the basic stiffeners in one hand and, give a better stability along the plan by a reasonable distribution along the plan. The post-buckling range is enhanced in fact that the structure buckles locally in a first stage. 
The structures $\mathrm{A}$ and $\mathrm{C}$ reach its ultimate bearing capacity at $323 \mathrm{KN}$ and $337 \mathrm{KN}$ respectively, we can realize the importance of the continuity of stiffening and sub-stiffening along the load axis since the structure $\mathrm{C}$ represents the lowest strength efficiency, even it is reinforced in its transverse direction. The post buckling range is not great enough to reach the bearing capacity shown by the structure $\mathrm{B}$. The curvilinear sub-stiffeners are not adequate for the uniaxial force: it is due to the non-sufficient continuity along the direction of the load that the structure start to buckle, goes from local to global in a short range.

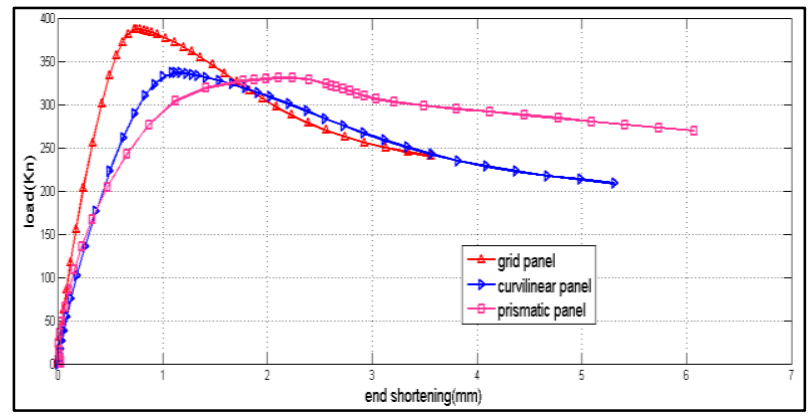

Figure 8. Non-linear RIKS algorithm for load Vs end shortening (Cases A, B and C).

We notice the poor post buckling range of the structural panel design (A), which is due to buckling response. In a first stage, it goes on a partial buckling with an important number of half wavelet.

\section{3 predicted collapse mode}

Studying the instability process refers to state the ultimate strength capacity which is known as the bearing load, the nonlinear RIKS algorithm performs the behavior of the three proposed design. The damage of the structures is predicted at the bearing critical load, our goal is to try to understand how and when the collapse may happen after the ultimate load:

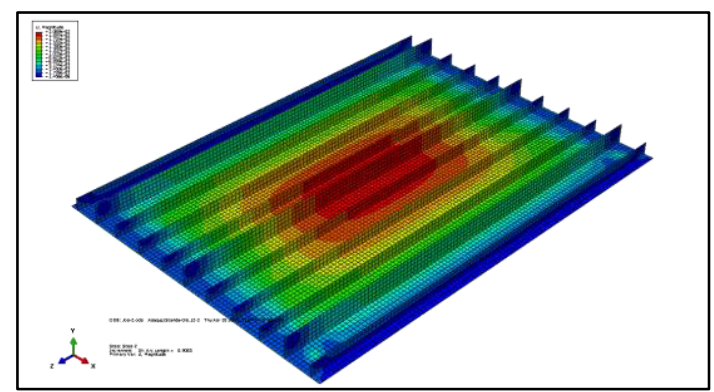

(A)

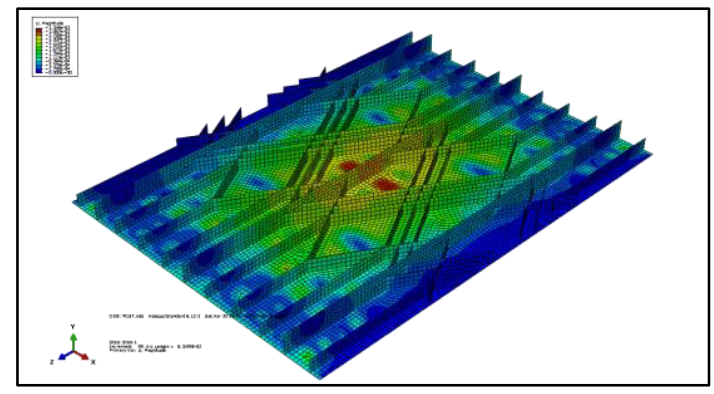

(B)

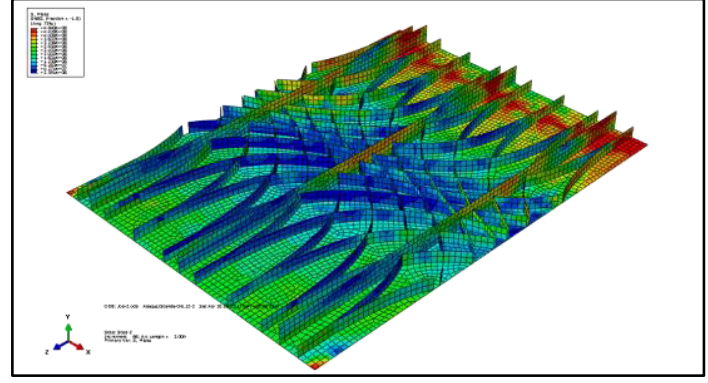

(C)

Figure 9. Predicted collapse modes of the proposed panels (Cases A, B and C).

The structure A, after reaching its ultimate strength capacity will collapse in a mode that both skin, the stiffeners and sub-stiffeners are affected. The partial buckling occur in the first stage affect the stability of the structure, lead it to a speedy instability and goes from partial to over.

The structure $\mathrm{B}$ represent a lesser ratio load/displacement, which is due to the, interaction between stiffeners and sub-stiffeners. the stress, is more located of the stiffeners so the collapse of the panel is predicted when the stiffeners breakdown( the substiffeners have no capacity to carry more loads, its designed to enhance the buckling performance by avoiding the overall buckling in first phase.

The structure $\mathrm{C}$ represents, a similar behavior shown by the structure A, the stiffeners, sub-stiffeners and the skin plate lose their stability, which goes on an overall buckling. The curvilinear sub-stiffeners cannot locate the stress caused by the axial load along the plan for longer, the panel buckle locally in a first stage, start to lose its stability and end up with failure in all directions.

\section{Conclusion}

The recent work is a selective study of sub-stiffening of the stiffened panels. An overall study about it leads us to think about the type of sub-stiffening, the dimensioning and how many sub-stiffener needed in a cross section. The compromise loading limits to weight saving should be respected. The results of simulation show that comparing to a normal stiffened panel, sub-stiffening improves the stability performance of the panel against the mechanical charging. :

The type of stiffening and sub-stiffening should take into consideration the type of loading. As for structure B, it may not give such a better performance for complicated loads like coupled compression-torsion.

The sub-stiffening is a second reinforcement for a better stability of the panels, it helps to locate the buckling on the skin and avoid the overall buckling.

The compromised aspect better performance with weight saving should take in care the load direction, that pass by ensuring the reinforcement in its direction first then, looking for a better distribution on the plan. Further numerical studies will focus on the response of such structures to multi-axis loads with design guidelines and outline of topology optimization. 


\section{References}

1. Khvyiuzov A, Xu YM. Initil buckling of compressed rectangular panels with variable stiffener sizes. Advanced Materials Research, 915-916D (2014).

2. Bushnell and C. Rankin, "Optimum design of stiffened panels with sub-stiffeners," in Proceedings of the forty sixth AIAA/ASME/ASCE/AHS/ASC structures, structural dynamics \& materials conference. Austin, Texas, pp. 18-21, (2005).

3. Wang HM. Additive layer manufacturing technology for high performance of metallic structure, opening new page of defence manufacture. Defense Manufacture Technology, (03):003, (2013)

4. Ni Y, Xu YM. Research on the stability of metallic sub-stiffening structure and its optimization under uniaxial loading. Acta Aeronautica et Astronautica Sinica. Jan 25, 35 (2014)

5. Xu YM, Li SZ. Approximate Calculation Method of Buckling Load on Intergral Sub-stiffened Panel. Journal of Beijing University of Aeronautics and Astronautics (2014)

6. D. Quinn, A. Murphy, W. McEwan, and F. Lemaitre, "Stiffened panel stability behaviour and performance gains with plate prismatic sub-stiffening," ThinWalled Struct., 47, no. 12, pp. 1457-1468, (2009).

7. B. W. Schafer, "Local, distortional, and Euler buckling of thin-walled columns," J. Struct. Eng., 128, no. 3, pp. 289-299, (2002).

8. G. L. Farley, "Selective reinforcement to enhance the structural performance of metallic compression panels," in Abstract submitted to 45th AIAA/ASME/ASCE/AHS/ASCSDM Conference, Palm Springs, CA, (2004).

9. G. Grondin, A. . Elwi, and J. J. . Cheng, "Buckling of stiffened steel plates - a parametric study," J. Constr. Steel Res., 50, no. 2, pp. 151-175, (1999).

10. R. M. F. Paulo, F. Teixeira-Dias, and R. A. F. Valente, "Numerical simulation of aluminium stiffened panels subjected to axial compression: Sensitivity analyses to initial geometrical imperfections and material properties," Thin-Walled Struct., 62, pp. 65-74, (2013)

11. Mulani SB, Slemp WCH, Kapania RK. EBF3PanelOpt: An optimization framework for curvilinear blade-stiffened panels. Thin-Walled Structures, 63: pp.13-26,(2013)

12. D. G. Stamatelos, G. N. Labeas, and K. I. Tserpes, "Analytical calculation of local buckling and postbuckling behavior of isotropic and orthotropic stiffened panels," Thin-Walled Struct., 49, no. 3, pp. 422-430, (2011).

13. X. Wang, H. Sun, A. Akiyama, and A. Du, "Buckling and ultimate strength of aluminium plates and stiffened panels in marine structures," in Fifth International forum on aluminium ships. Tokyo, Japan, (2005).

14. L. Brubak and J. Hellesland, "Semi-analytical postbuckling and strength analysis of arbitrarily stiffened plates in local and global bending," ThinWalled Struct., 45, no. 6, pp. 620-633, (2007).

15. J. K. Paik and B. J. Kim, "Ultimate strength formulations for stiffened panels under combined axial load, in-plane bending and lateral pressure: a benchmark study," Thin-Walled Struct., 40, no. 1, pp. 45-83, (2002).

16. T. Kubiak, Nonlinear Plate Theory for Postbuckling Behaviour of Thin-Walled Structures Under Static and Dynamic Load. INTECH Open Access Publisher, (2012).

17. Barrière, L., Marguet, S., Castanié, B. et Cresta, P..A computational strategy for post-buckling analysis of large stiffened structures. In28th International Council in Aeronautical Sciences, ICAS2012, Brisbane, Autralia (2012).

18. Barrière, L., Marguet, S., Castanié, B. et Cresta, P..A. Modelling strategies for post-buckling analysis of large stiffened structures In 17th International Conference on Composite Structures, ICCS17, Porto,Portugal(2013). 